Journal of

(C) All rights are reserved by Arslan et al.

\title{
Mechanism and Treatment of Genital Injuries in Pediatric and Adolescent Girls: Data from Two Regional Centers in Turkey
}

Keywords: Genital Injury; Adolesc ent; Pediatric Age; Treatment

\begin{abstract}
Background/purpose: The aim of this study is to evaluate and compare the etiology, classification and treatment of genital injuries in pediatric and adolescent age group girls.

Material and Method: Pediatric and adolescent age group girls who presented to our clinic with a perineum injury between January 2010 and January 2014 were included in the study. The etiology, mechanism, localization and treatment of the injury were retrospec tively a nalyzed for each group.

Results: The mean ages of the groups were 7.17 (min 3 - max 10) years in the pediatric age group and 14.24 ( $\min 11$ - max 18) years in the adolescent age group. According to mechanism of injuries the most common type was straddle type injuries in both groups. Surgical intervention was required for 5 (17\%) patients in the pediatric age group and for 16 (64\%) patients in the adolescent a ge group. All cases underwent primary suturing. The pediatric age group was found to be transported to the hospital later than the adolescent age group $(40.5 \pm 22.6 \mathrm{~min}$ and $36.6 \pm 29.5 \mathrm{~min}$, respectively).

Conclusion: The severity of the injury was closely associated with the age. Primary suturing was the most common surgical procedure in both age groups. The possibility of sexual assault should not be overlooked, especially in injuries of the fourchette combined with the labia.
\end{abstract}

\section{Introduction}

Genital injuries are uncommon in adolescent and children. The most common cause of genital injuries in children and adolescents is sexual assault in developed countries and is accidents in underdeveloped and developing countries [1-5]. Female genitalia can easily be injured by trauma especially in prepubertal girls because of tissue fragility although surgery is rarely needed. In case of genital trauma a detailed evaluation including the examination of the hymen is required for both determining the treatment and further possible legal actions. The treatments vary according to the cause of the injury, the presence of additional organ injuries and time between the injury and presentation to the hospital. The future gynecologic and sexual development should be considered in the evaluation and the treatment of the patient.

The aim of this study is to evaluate the etiology, classification and treatment of genital injuries in the pediatric and adolescent girls.

\section{Material and Method}

\section{Patient selection and classification}

Pediatric and adolescent age group girls who presented to our clinic because of genital injury between January 2010 and January

\section{Forensic}

\section{Investigation}

Mustafa Kaplanoglu ${ }^{1}$, D. Sümeyra Demirkıran², Atilla Karateke ${ }^{3}$ and M. Mustafa Arslan ${ }^{2 *}$

${ }^{1}$ Adiyaman University School of Medicine, Department of Obstetric and Gynecology, Adiyaman, Turkey

${ }^{2}$ Mustafa Kemal University School of Medicine, Medical Faculty, Department of Forensic Medicine, Antakya, Turkey

${ }^{3}$ Hatay Goverment Hospital, Department of ObstetricandGynecology, Antakya, Turkey

\section{Address for Correspondence}

Dr. Muhammed Mustafa Arslan, MD, Mustafa Kemal University, Tayfur Ata SokmenSchool of Medicine, Deparment of Forensic Medicine, Antakya, Turkey, Phone: 90-5052290306; Fax: 90-326-245-53-05; E-mail: mmustafaarslan@yahoo.com

Submission: 28 August, 2014

Accepted: 07 October, 2014

Published: 09 October, 2014

Reviewed \& Approved by: Dr. Mete Korkut Gülmen, Professor in the Department of Forensic Medicine at Cukurova University School of Medicine, Turkey

2014 were included in this study. The patients were divided into two groups as the pediatric age group ( $\leq 10$ years) and the adolescent age group (Age 11 to 19 years). Genital injuries were defined as clitoris, fourchette, vagina and labia, and combined injuries. The need for surgical treatment was recorded during the evaluation of the patients. Any procedure including primary suturing is accepted as surgical intervention. The place of intervention is recorded as emergency room or operating room.

\section{Descriptions}

The trauma mechanism was described as straddle, non-straddle blunt, and laceration or coital as follows:

Straddle: Injuries following falling or sitting on the perineal area with the legs open.

Non-straddle Blunt: Injury-causing trauma from outside factors other than falling (such as a ball or stone).

Laceration: Trauma that causes a cut or laceration in the genital and perineal area due to falling or an outside factor.

Coital: Trauma caused by sexual intercourse whether penetration occurred or not.

\section{Data records}

(a) The patient's age at admission, (b) trauma mechanism and localization, (c) time between the injury and the presentation at the hospital, and (d) need for surgical intervention and place of intervention were recorded by all authors as a routine procedure.

\section{Statistical analysis}

Statistical analysis was done using the Statistical Package for the Social Sciences software version 13.0 (SPSS Inc., Chicago, Ill., USA). Continuous variables were compared between groups using Student's 
Citation: Kaplanoglu M, Demirkıran DS, Karateke A, Arslan MM. Mechanism and Treatment of Genital Injuries in Pediatric and Adolescent Girls: Data from Two Regional Centers in Turkey. J Forensic Investigation. 2014;2(3): 3.

ISSN: 2330-0396

paired t test. Discrete variables were compared with $\chi 2$ or Fisher's Exact tests when appropriate. Statistical significance was defined as $\mathrm{P} \leq 0.05$.

\section{Results}

The mean age in the pediatric group was $7.1 \pm 1.7(\min 3-\max$ 10) years old and in adolescent group were $14.2 \pm 2.2(\min 11-\max$ 18) years old

\section{Mechanism of Injuries}

Straddle type injuries were the most common type in both groups (pediatric age group 15 [53.6\%], adolescent age group 12 [48\%] patients). The least common type of injury was coital in the child age group $1[3.6 \%]$ ) and laceration in adolescent age group 1 [4\%].

\section{Arrival time to hospital}

When the duration until presentation at the hospital after the injury was evaluated, there was a significant difference between the groups. This duration was found to be longer in the pediatric age group cases than the adolescent age group cases $(40.5 \pm 22.6 \mathrm{~min}$ and $36.6 \pm 29.5$ min respectively).

\section{Severity and location of Injuries}

There was also a statistically significant difference between the groups regarding the need for intervention after the trauma. Most of the injuries required only an observation or primary suturing that could be done in emergency room. Need for primary suturing was $17.9 \%$ in the pediatric age group and $64 \%$ in the adolescent age group. Surgical repair in operating room was performed in 3 patients in the pediatric age group and 1 patient in the adolescent age group. All cases were discharged within the same day. No additional surgery was required.

No statistically significant difference was found between the groups in terms of injury localization or additional organ damage (Table 1). The labia were the most frequent site of injury in both groups. Labia injuries were accompanied by fourchette and clitoris injuries in 2 (7.1\%) patients in the pediatric age group and in $6(24 \%)$ patients in the adolescent age group.

The injury was coital in 1 of these patients (in the adolescent age group) and required primary repair. She was injured during sexual intercourse with her boyfriend. For all cases when any suspect of abuse existed legal authorities were informed.

\section{Discussion}

Genital injury in pediatric and adolescent patients usually occurs after an accident or sexual abuse [6]. The localization and the severity of the injury is very important regarding the future gynecological and sexual development of the patient. Perineal injuries constitute $0.2 \%$ of the injuries in girls under the age of 15 [7]. Female genitalia is more fragile in prepubertal period because of low levels of estrogen. The effects of estrogen advance by age and that increases tissue flexibility. Therefore limited injuries with less morbidity occur [8].

Perineal and genital injuries in the prepubertal females usually occur due to trauma, especially as a result of falling with open legs on a bicycle, chair or pool wall [9]. Such injuries are usually in form of contusion type laceration and hematoma [10]. In a study of 358
Table 1: Demographic and clinical features of cases.

\begin{tabular}{|c|c|c|c|}
\hline & $\begin{array}{l}\text { Pediatric age } \\
\text { Group }\end{array}$ & $\begin{array}{l}\text { Adolescent age } \\
\text { Group }\end{array}$ & p \\
\hline Age (years $\pm S D$ ) & $7,1 \pm 1,7$ & $14,2 \pm 2,2$ & $\begin{array}{c}< \\
0.05\end{array}$ \\
\hline Mechanism n(\%) & & & $\begin{array}{c}> \\
0.05\end{array}$ \\
\hline Straddle & $15(53.6)$ & $12(48)$ & \\
\hline Blund & $9(32.1)$ & $6(24)$ & \\
\hline Coital & $1(3.6)$ & $6(24)$ & \\
\hline Laceration & $3(10.7)$ & $1(4)$ & \\
\hline Wound location n(\%) & & & $\begin{array}{c}> \\
0.05\end{array}$ \\
\hline Clitoris & $2(7.1)$ & $2(8)$ & \\
\hline Fourchette & $3(10.8)$ & $4(16)$ & \\
\hline Labia & $21(75)$ & $13(52)$ & \\
\hline Labia and clitoris & $2(7.1)$ & $4(16)$ & \\
\hline Labia and fourchette & $0(0)$ & $2(8)$ & \\
\hline Surgical treatmet n(\%) & & & $\begin{array}{c}< \\
0.05\end{array}$ \\
\hline Primary suturation & $5(17.9)$ & $16(64)$ & \\
\hline Exmiination only & $23(82.1)$ & $9(36)$ & \\
\hline $\begin{array}{l}\text { Additional organ damage } \\
(\%)\end{array}$ & & & $\begin{array}{c}> \\
0.05\end{array}$ \\
\hline Yes & $2(7.1)$ & $3(12)$ & \\
\hline No & 26(92.9) & $22(88)$ & \\
\hline $\begin{array}{l}\text { Arrived time tohospital } \\
\text { (min) }\end{array}$ & $40.5 \pm 22.6$ & $36.3 \pm 29.5$ & \\
\hline
\end{tabular}

$n$, number of patients

$S D$, Standart Deviations

female pediatric patients who experienced blunt perineal trauma, falls and bicycle-related injuries were more prevalent in children younger than 9 years old, and assaults in children between 0 and 4 years old [3]. Other studies on pediatric and adolescent perineal injuries, need for surgical intervention was found between $15 \%$ to $20 \%[11,12]$. Straddle type injury was significantly most common type injury in both groups of our study. It was usually associated with swing and bicycle accidents. This result is consistent with the literature [12]. Non-straddle blunt type injury usually occurred due to being hit by a stick or ball during a game. The ability to move and protect oneself increases with advancing age in children and adolescents. Therefore the risk of injury from predictable and preventable trauma may decrease with age. Laceration injuries due to falls are more frequently detected in children under the age of 10. Laceration injury was identified in $10.7 \%$ of the cases in the pediatric age group in our study and required primary repair in the operating room.

Injuries following sexual assault constitute another type of injury. The vagina, anus, and rectum were more commonly injured in the sexually abused girls than other type injuries. Other organ damages are not common in this type of injuries. Adolescent females were exposed to sexual assault more frequently [13]. Other studies have also reported high rates of sexual assault in the adolescent group $[14,15]$. A high incidence in the $0-4$ year's age group was also reported [3]. This is due to the victim being unprotected and often having inadequate awareness. A significantly higher prevalence was found in 
Citation: Kaplanoglu M, Demirkıran DS, Karateke A, Arslan MM. Mechanism and Treatment of Genital Injuries in Pediatric and Adolescent Girls: Data from Two Regional Centers in Turkey. J Forensic Investigation. 2014;2(3): 3.

the adolescent age group in our study (6 (24\%)). Patients between the ages of 14 and 18 years are particularly at risk. In our cases, primary suturing was performed and no complications were detected. Material for forensic evidence was obtained in examination of all sexual assault patients. Prophylaxis for sexually transmitted diseases and pregnancy test were also made.

Injuries were most commonly localized in the labia in both groups and did not need additional surgical intervention. The fourchette or clitoris was also injured in $2(7.1 \%)$ patients in the pediatric group and in $6(24 \%)$ patients in the adolescent age group. The mean rate of other sexual assault injuries accompanying labial injuries is about $8 \%$ in the literature. The possibility of sexual assault should not be ignored in this group of patients. A hymen examination should be performed [16-19]. The fourchette injuries may also be a sign of sexual assault. Other injuries are extremity injuries that frequently occur after falls and did not require advanced investigation or treatment.

Sexual assault should be considered in pediatric and adolescent injuries in case of genital injuries. Sexual assault cases may not come forward due to threats, fear or society's misconceptions. The actual rate of children and adolescents subjected to sexual assault is therefore higher than that reported [15]. Sexual assault should be suspected especially in case of age-inappropriate trauma, sexual injury other than the perineum, and inconsistency of the lesions with the history.

The duration between the injury and the patient's presentation at the hospital is important in terms of treatment and evaluating the evidences in legal cases. Prompt intervention may prevent serious morbidity even mortality, especially in bleeding patients. Physical examination findings and the presence of biological evidence that will determine the suspect are very important in sexual assault cases. The adolescent age group was found to be brought faster to the hospital after the injury in our study. We believe the reason is the patient could express herself better and could be taken to the hospital by others without waiting for the family. The operating room was required for 3 patients in the pediatric age group and none in the adolescent group following the initial examination. These patients had labial or labia-clitoris injuries that did not require vaginoscopy, cystoscopy or proctoscopy and were treated with hemostasis and primary suturing.

Limitations of this study include its retrospective nature and involvement of multiple examiners using non-standardized documentation. All data of our study has been received from hospital records. Mechanisms of injuries were usually based on the histories.

\section{Conclusion}

The most common cause of genital injuries in both groups in our study was straddle type injury and this was consistent with the literature. Usually no additional organ damage was present and surgical intervention was rarely needed. Primary suturing was the most commonly required surgical procedure in all age groups. The presence of fourchette and hymen injury should be accepted as warning signs of sexual assault. Sexual abuse should always be considered and ruled out by a thorough history that correlates with the physical examination findings. We found that the adolescent age group came faster to the hospital after the injury.

\section{References}

1. Kadish HA, Schunk JE, Britton H (1998) Paediatric male rectal and genita trauma: accidental and non-accidental injuries. Pediatr Emerg Care 14: 9598.

2. Mohr AM, Pham AM, Lavery RF, Sifri Z, Bargman V, et al. (2003) Management of trauma to the male external genitalia: the usefulness of American Association for the Surgery of Trauma organ injury scales. J Urol 170: 2311-2315.

3. Scheidler MG, Schultz BL, Schall L, Ford HR (2000) Mechanism of blunt perineal injury in female pediatric patients. J Pediatr Surg 35: 1317-1319.

4. Güzel A, Ersoy B, Doğrusoy Y, Küçükuğurluoğlu Y, Altinel T, et al. (2006) The evaluation of bicycle accidents that were admitted to a pediatric emergency department. Ulus Travma Acil Cerrahi Derg 12: 299-304.

5. Özkürkçügil C, Ayan S, Uçar C, Gültekin Y (1997) The general specialties of genitourinary trauma in our clinic. Ulus Travma Acil Cerrahi Derg 3: 218-221.

6. Benjamins LJ (2009) Genital trauma in pediatric and adolescent females. J Pediatr Adolesc Gynecol 22: 129-133.

7. Bond GR, Dowd MD, Landsman I, Rimza M (1995) Unintentional perinea injury in prepubescent girls: a multicenter prospective report of 56 girls. Pediatrics 95: 628-631.

8. Gabriel NM, Clayton M, Starling SP (2009) Vaginal laceration as a result of bluntvehicular trauma. J Pediatr Adolesc Gynecol 22: e166-e168.

9. Kılıçarslan H, Ayan S, Gökçe G, Kayağan E, Gültekin EY (2001) A retrospective analysis of genitourinary trauma in pediatric patients. Ulus Travma Acil Cerrahi Derg 7:110-112.

10. Spitzer RF, Kives S, Caccia N, Ornstein M, Goia C, et al. (2008) Retrospective review of unintentional female genita Itrauma at a pediatric referral center. Pediatr Emerg Care 24: 831-835.

11. Dowd D, Fitzmaurice L, Knapp JF, Mooney D (1994) The interpretation of urogenital findings in children with straddle injuries. J Pediatr Surg 29: 7-10.

12. Iqbal CW, Jrebi NY, Zielinski MD, Benavente-Chenhalls LA, Cullinane DC, et al. (2010) Patterns of accidental genital trauma in young girls and indications for operative management. J Pediatr Surg 45:930-933.

13. Navratil F (2003) Sexual abuse in adolescence: patient assessment, necessity and meaning of the physical examination. Gynakol Geburtshilfliche Rundsch 43:146-151.

14. Jones JS, Rossman L, Wynn BN, Dunnuck C, Schwartz N (2003) Comparative analysis of adult versus adolescent sexual assault: epidemiology and patterns of anogenital injury. Acad Emerg Med 10: 872-877.

15. Kar H, Arslan MM, Çekin N, Akcan R, Hilal A (2010) Sexual Assault in Childhood and Adolescence; a Survey Study. Eur J Social Sci 13: 549-555.

16. Pokorny SF, Pokorny WJ, Kramer W (1992) Acute genital injury in the prepubertal girl. Am J Obstet Gynecol 166:1461-1466.

17. McCann J, Miyamoto S, Boyle C, Rogers K (2007) Healing of nonhymenal genital injuries in prepubertal and adolescent girls: a descriptive study. Pediatrics 120:1000-10011.

18. Heppenstall-Heger A, McConnell G, Ticson L, Guerra L, Lister J, et al. (2003) Healing patterns in anogenital injuries: a longitudinal study of injuries with sexual abuse, accidental injuries, or genital surgery in the preadolescent child. Pediatrics 112: 829-837.

19. Heger AH, Ticson L, Guerra L, Lister J, Zaragoza T, et al. (2002) Appearance of the genitalia in girls selected for non-abuse review of hymenal morphology and non-specific findings. J Pediatr Adolesc Gynecol 15: 27-35. 